\title{
Feasibility study on high-speed rail and air cooperation
}

\author{
Jianghao Luo \\ School of Transport and Transportation, Beijing Jiaotong University, Beijing, PRC \\ jianghaoluo@gmail.com
}

Keywords: air transport, rail, hub-spoke, cooperation, energy consumption

Abstract. The development of air transport and high-speed rail (HSR) is facing two problems. One is competition, having been stated in many literatures focusing on the economic distances; and another is stresses from large investments, energy consumption and environmental degradation. In this paper, the feasibility of HSR-air transport cooperation is discussed, aiming to prevent excessive service and reduce emissions, but not hurt travelers. The feasible regions are calculated based on a total cost model and Lotka-Volterra equation, identifying in which situations air and HSR could cooperate. Based on this method, some measures are proposed to increase the possibility of cooperation. Some typical city-pairs in China are empirically discussed and the cooperation indexes are calculated.

\section{Introduction}

Competition and substitution are discussed repeated since HSR emerging. Air transport and HSR involve strong competition between two big cities with a strong business relationship [1,2], such as London-Paris, Beijing-Shanghai. However, the competition strategies usually cause higher frequency, both air and HSR operators[3], and air transport and rail competition raises the question of impact on the environment. The operators and policy makers face two problems: firstly, is duplicate transport services supplied by HSR and air necessary? Can air and HSR cooperate?

According to a summary of empirical references, studies on air-HSR complementary and cooperation are relatively rare. HSR can provide feeding services to long haul air services in hub airports, particularly in hub airports with HRS stations, especially in Europe and US [4]. Infrastructure, schedule and frequency are key factors to a successful airport-HSR connection.

From the perspective of social and environment, it is confirmed that HSR is more friendly, and cooperation and intermodality is environmental efficient $[5,6]$. The Intermodal agreement aims at one complete journey with a fast and seamless transfer between the modes. However, from the perspective of passengers and operators, the former would choice a suitable transport mode according to total travel cost, and the latter focus mostly on the profits. So that the intermodal integration desire dose not always lead to a satisfying ends, especially in China. And in some cases, the competition is sharp, HSR also compete with air transport in long corridors, much more than 500 600 km distance, as mentioned in previous studies. For example, Quzhou- Hangzhou airline had been ended, and the air transport and HSR operators compete in Quzhou-Beijing corridor, although the operations are not enough efficient. Why the complementary and integration can hardly happen in this area? The paper is organized as follows. The basic model involving total travel cost and Lotka-Volterra equation is developed in Section 2. Section 3 analyzes some typical city-pairs and transport corridors in China and describes the results. Section 3 draws a discussion on model parameters and concludes.

\section{Methodology and model}

Theoretical framework. The studies below are based on two premises: the passenger will choose suitable mode considering travel time and money cost, and the operators will abandon the market only when seldom passengers choose the mode, otherwise they will stay in the market, regardless of the environment problems. 


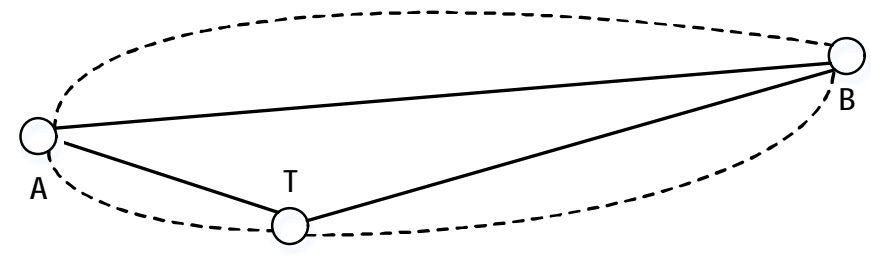

Airflights

Figure 1 Simplest network and routes

It is assumed the simplest possible system with three cities (A, B and T) as shown in Fig.1. AT and BT are always served nonstop either by air or HSR, depending on economic distance. AB can be served either directly or indirectly with a transfer via hub $\mathrm{T}$. In the direct service market air and rail are substitutes for each other, and competition is inevitable. The study is focused on $\mathrm{AB}$ corridor.

Basic Model. The model of density-dependent logistic growth is continually used in many theoretical and applied studies, especially in connection with problems of competition. In general, the standard two-species Lotka-Volterra equation is given by:

$$
\frac{d N}{d t}=r N\left(\frac{K-N}{K}\right)
$$

where $t$ is time, $N$ population size (or density), $r$ the highest per capita growth rate which is approximated at $N$ close to zero, and $K$ is the population size at which growth will stop. In this paper, $r$ is the internal increase rate of number of corridor travelers, which is decided by regional population and economic increase; $K$ is the airline or rail line capability. In this model, the kind of inter-specific interaction is assumed to be not fixed, and it depends on the system state. Three possible situations for the interspecific relationship are shown in Table. 1. Here $K_{r}$ and $K_{a}$ respectively means rail and air transport capacity, $\lambda_{r a}$ and $\lambda_{a r}$ respectively the competition coefficient of rail or air in a certain market. And (I) (IV) four quadrants present possible kinds of air-HSR interaction. When (I) or (III) hold, one of the species wipes out the other one, In case (IV) the competition among the species is weak and coexistence is expected. Case (II), called strong competition, is more complex. In this situation, the equilibrium is unstable..

Table 1. Four Possible Kinds of Air-HSR Interactions

\begin{tabular}{l|l|l}
\hline & $\frac{K_{r}}{\lambda_{r a}}<K_{a}$ & $\frac{K_{r}}{\lambda_{r a}}>K_{a}$ \\
\hline$\frac{K_{a}}{\lambda_{a r}}<K_{r}$ & (II) Not confirmed & (I) Air transport is substituted by HSR \\
\hline$\frac{K_{a}}{\lambda_{a r}}>K_{r}$ & (III) HSR is substituted by air transport & (IV) Air transport and HSR coexsist \\
\hline
\end{tabular}

The Competition Coefficient. The competition coefficient $\lambda$ is decided by traveler's total costs $T C_{i}\left(i=\right.$ air, HSR). And $T C_{i}$ can be divided into two parts as shown in Fig. 1: travel time value $\left(C^{T}{ }_{i}\right)$ and ticket cost $\left(C^{C}\right)$, the key factor in the decision process of a traveler in choosing a transportation mode. Unlike traditional rail, the level of comfort in HSR is similar to air, so that the cost of comfort is not considered here.

$$
T C_{i}=C^{T}{ }_{i}+C^{C}{ }_{i}=T_{i} v+C_{i}^{c}
$$

The previous literatures typically monetize the value of travel time $\left(C^{T}{ }_{i}\right)$ using the average hourly wage of a passenger $(v)$ and travel time $\left(T_{i}\right)$, varying by the assumption of the typical passenger ' $\mathrm{s}$ purpose of travel and personal preferences. In this paper the time value is not monetize, but compared with ticket cost using the concept of competition:

$$
\lambda_{r a}=\frac{T_{r}}{T_{a}} \quad \lambda_{a r}=\frac{C^{c}{ }_{a}}{C^{c}{ }_{r}} \quad \text { and } \quad T_{i}=a_{i}+\frac{l_{i}}{s_{i}}, C^{c}{ }_{i}=l_{i} \cdot p_{i}
$$


Where $a_{i}$ ( $i=$ air, HSR) is the access, egress and average waiting time of HSR or air transport; $l_{i}$ ( $i=$ air, HSR) is the distance of airline or rail line, and usually $l_{\text {air }}$ is shorter; $s_{i}$ is the speed of aircraft or train; $p_{i}$ is the ticket price. Travel value is a key factor affecting mode choice and competition strategies. Air transport users exhibit substantially higher values for saving travel time than HSR travelers ([7]), and the competitive power of air transport $\lambda_{r a}$ is decided by the ratio of air and HSR travel time. Moreover, HSR travelers pay more attention to ticket cost than air travelers, and the competitive power of HSR $\lambda_{a r}$ is estimated by the ration of HSR and air ticket costs, involving the ticket prices and travel distances.

\section{A case study in China}

Studied city-pairs. Four typical transport corridors in China are selected, involving a hub city (Beijing), 4 mid-hub cities (Hangzhou, Guiyang, Chengdu, and Xi' an) and 4 regional cities (Quzhou, Zunyi, Yibin and Yulin), as shown in Fig. 2.

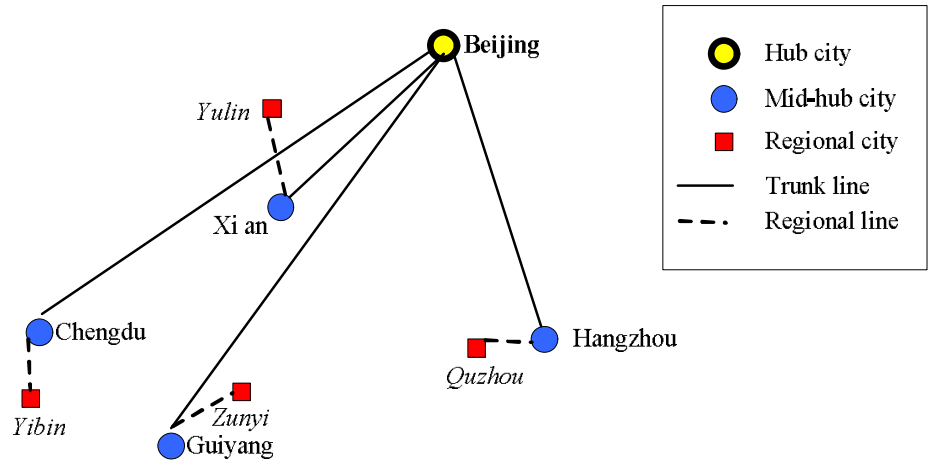

Fig. 2. Studied City-pairs and Corridors

Parameters selection. The access time in Europe hub-spoke airports and train station is 1 and 0.5 hour respectively, while takeoff/landing times are both $0.25 \mathrm{~h}[8]$. In the case of Madrid-Barcelona, the access and egress time of air transport is $73 \mathrm{~min}$ and rail is $68 \mathrm{~min}$, while the waiting time is 58 and 28min separately[9]. According the experienced studies and actual data in China, the parameters used in this case are listed in Table 2.

Table 2. Parameters and Levels of the Experiment.

\begin{tabular}{l|c|c|c}
\hline Parameters & Unit & Air & HSR \\
\hline Access and egress time & $\mathrm{h}$ & 2 & 1 \\
\hline Average velocity & $\mathrm{km} / \mathrm{h}$ & 250 & 700 \\
\hline Price rate & yuan $/ \mathrm{km}$. person & 0.4 & 1 \\
\hline discount & $\%$ & 55 & 100 \\
\hline
\end{tabular}

Table 3.shows the competition coefficient estimates results, as specified in Eq.(3), for trunk line and regional line separately. The two parameters $\mathrm{Q}^{\mathrm{T}}$ and $\mathrm{Q}^{\mathrm{R}}$ indicates which quadrant the trunk or regional line is located. The meaning of quadrants of I IV are depicted in Table 1.

Competitive market. The result of $\left(Q^{T}=I V\right)$ means that HSRQ and air transport coexisting in this corridor. Both the operators of HSR and air can hardly wipe the other out, and none of them would like quit this market. The cooperation with another mode between regional line and trunk line obviously causing income reduction is not considered, even if the cooperation is efficient to capacity utilization and energy consumption. The operators seldom cooperate and cline to open new, non-stop services, especially in densely populated city-pairs. Here is a case of Beijing-Quzhou, as shown in table 2. Although the cooperation between air and rail via hub city Hangzhou has been expected for many years, finally the regional air service from Quzhou to Hangzhou is canceled and the non-stop services from Quzhou to Beijing separately supplied by HSR and air are now in operation. 
Monopolistic market. The result of $\left(Q^{T}=Q^{R}=I I I\right.$ or $\left.Q^{T}=Q^{R}=I\right)$ means that the markets in these city-pairs are completely controlled by air or HSR. Such mode seldom searches for cooperation. The case is Beijing-Chengdu-Yibin. Now the non-stop train from Beijing to Yibin is not open.

Cooperation market. If $\mathrm{Q}^{\mathrm{T}}=\mathrm{III}$ and $\mathrm{Q}^{\mathrm{R}}=\mathrm{I}$, or $\mathrm{Q}^{\mathrm{T}}=$ Iand $\mathrm{Q}^{\mathrm{R}}=\mathrm{III}$, the cooperation is expectable. In such city-pairs, the effort aiming at HSR-air intermodal agreement will not be wasted. And the cooperation can improve the travelers' experiences and aircraft/train utilization ratio.

Table 3. Competition Index and Quadrant

\begin{tabular}{l|l|l|l|l|l|l|l|c}
\hline code & Trunk line & $\lambda_{a r}$ & $\lambda_{r a}$ & $\mathrm{Q}^{\mathrm{T}}$ & Regional line & $\lambda_{a r}$ & $\lambda_{r a}$ & $\mathrm{Q}^{\mathrm{R}}$ \\
\hline BHQ & Beijing-Hangzhou & 0.59 & 0.82 & IV & Quzhou-Hangzhou & 1.18 & 0.84 & $\mathrm{I}$ \\
\hline BGZ & Beijing-Guiyang & 0.40 & 1.05 & III & Zunyi-Guiyang & 1.13 & 1.00 & I \\
\hline BCY & Bejing-Chengdu & 0.40 & 1.12 & III & Yinbin-Chengdu & 0.98 & 1.19 & III \\
\hline BXY & Beijing-Xi'an & 0.57 & 0.95 & IV & Yulin-Xi'an & 0.78 & 0.99 & IV \\
\hline
\end{tabular}

\section{Discussion and Conclusion}

The results are based on the fixed parameters. However, the parameters are not stable in real world. The first parameter is $K_{i}$, the capacity of air or HSR. In some busy airports, the capacity of air transport is limited. For example, if $K_{a}=1$ and $K_{r}=2$, the possibility city-pairs will change. The second parameter is the ticket price discount of air transport. Reducing air transport price will expand cooperation zone. However, extremely low price policy can hardly last long. At last, the service levels of air and HSR in different lines are not the same, and the access/egress time, waiting time affect traveler's mode choice decision.

The model in this paper combined considerations of travelers and transport operators. The results are not the optimal solution, but can be accepted in real markets. According to this model, three kinds of markets are classified: the competition market, monopolistic market and cooperation market. The intermodal agreements and efforts aiming at one complete journey with a fast and seamless transfer between the modes can be more effective in cooperation markets.

\section{References}

[1] F. Pagliara, J.M. Vassallo, C. Román, High-Speed Rail Versus Air Transportation : Case Study of Madrid

- Barcelona, Spain, Transportation Research Record: Journal of the Transportation Research Board,No. 2289, Transportation Research Board of the National Academies, Washington,D.C, (2012) 10- 17.

[2] C. Behrens, E. Pels, Intermodal competition in the London-Paris passenger market: High-Speed Rail and air transport, J Urban Econ, 71 (2012) 278-288.

[3] F. Dobruszkes, High-speed rail and air transport competition in Western Europe: A supply-oriented perspective, Transport Policy, 18 (2011) 870-879.

[4] R.R.L. Clewlow, J.M. Sussman, H. Balakrishnan, Interaction of High-Speed Rail and Aviation: Exploring Air- Rail Connectivity, Transportation Research Record: Journal of the Transportation Research Board, No.

2266, Transportation Research Board of the National Academies, Washington,D.C., (2012) 1- 10.

[5] M. Zanin, R. Herranz, S. Ladousse, Environmental benefits of air-rail intermodality: The example of Madrid Barajas, Transport Res E-Log, 48 (2012) 1056-1063.

[6] T. D'Alfonso, C.M. Jiang, V. Bracaglia, Would competition between air transport and high-speed rail benefit environment and social welfare?, Transport Res B-Meth, 74 (2015) 118-137.

[7] C. Roman, J.C. Martin, R. Espino, E. Cherchi, J.D. Ortuzar, L.I. Rizzi, R.M. Gonzalez, F.J. Amador, Valuation of travel time savings for intercity travel: The Madrid-Barcelona corridor, Transport Policy, 36 (2014) 105-117.

[8] N. Adler, E. Pels, C. Nash, High-speed rail and air transport competition: Game engineering as tool for cost-benefit analysis, Transport Res B-Meth, 44 (2010) 812-833.

[9] C. Roman, R. Espino, J.C. Martin, Competition of high-speed train with air transport: The case of Madrid-Barcelona, J Air Transp Manag, 13 (2007) 277-284. 